\title{
SOLITARY FIBROUS TUMOR OF THE PLEURA MIMICKING PLEURAL EFFUSION
}

\section{Flávia Kessler Borges ${ }^{1,2}$, Caroline Machado Rotta Dornelles ${ }^{3}$, Analu Vivian ${ }^{2}$}

We describe a case of a 62-year-old female patient with dry cough over the last year. She was previously healthy, except for hypertension, and had no history of smoking. She sought medical care for mild dyspnea, wheezing, and cough. Firstly, chest X-ray suggested pleural effusion affecting about two-thirds of the left lung. A thoracentesis was tried without success.

During hospitalization, a chest computerized tomography (CT) scan was performed, showing a large lesion with slightly heterogeneous tumescent soft tissue attenuation occupying two-thirds of the left hemithorax, measuring $13 \times 15 \times 16 \mathrm{~cm}$, and displacing mediastinal structures contralaterally (figure 1). An ultrasound-guided thoracic biopsy was performed. Histopathological examination identified a mesenchymal neoplasm of spindle cells with low mitotic index and hypercellular areas alternating with predominantly collagenous areas, suggesting the diagnosis of solitary fibrous tumor of the pleura (SFTP).

The patient underwent thoracic surgery, which identified a strongly vascularized bulky oval lesion adhered to the diaphragm cranially and pressing the entire left lung (figure 2). Resection of the lesion and the diaphragmatic portion adhered to the tumor was performed in addition to inferior left lobe segmentectomy. The histopathological analysis confirmed a visceral SFTP without features of malignancy.

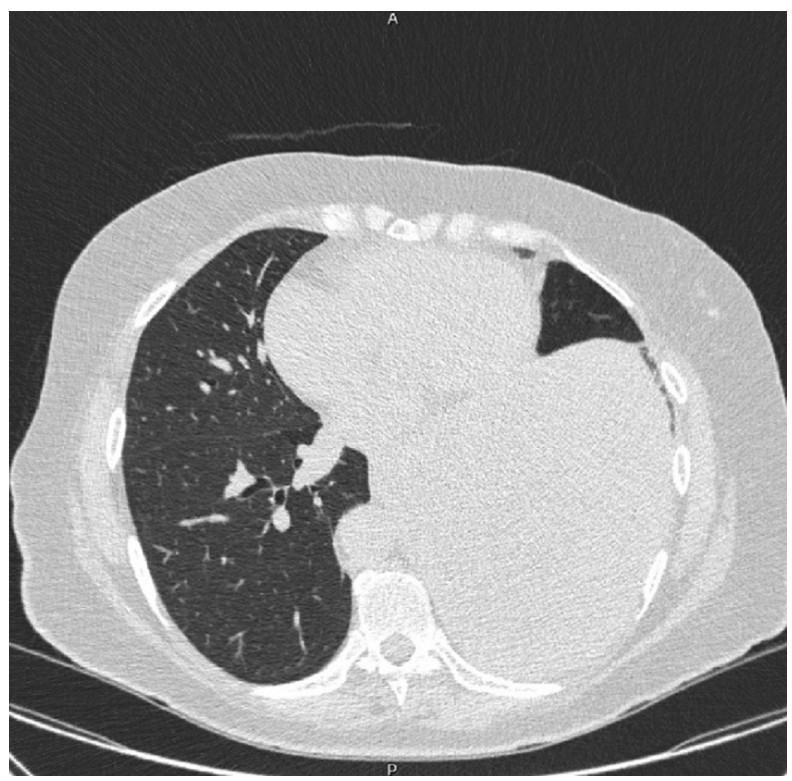

Figure 1: Chest computerized tomography (CT) showing a large lesion with slightly heterogeneous tumescent soft tissue attenuation occupying about two-thirds of the left hemithorax, measuring $13 \times 15 \times 16 \mathrm{~cm}$, and displacing mediastinal structures contralaterally. 


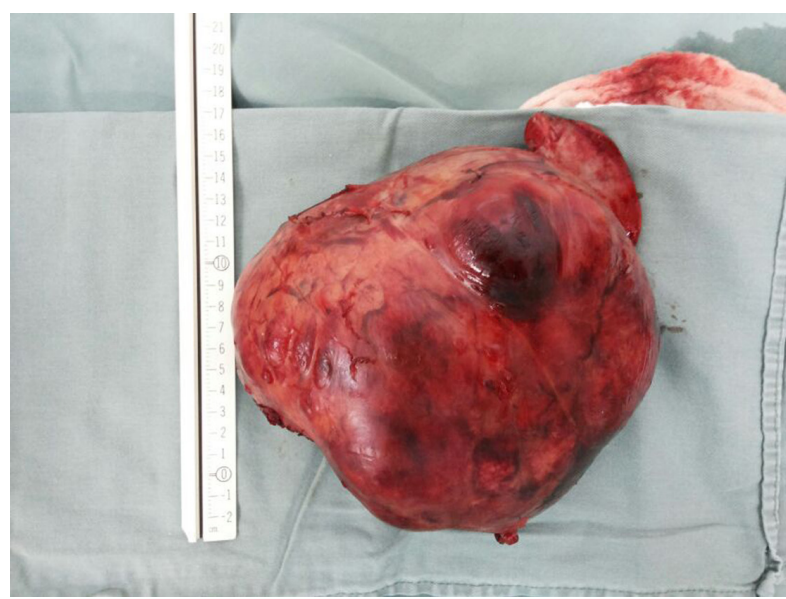

Figure 2: Macroscopic image identifying a strongly vascularized bulky oval lesion suggestive of fibrous tumor of the pleura.

SFTP is a rare, slow-growing pleural-based tumor of mesenchymal origin. This often benign lesion is asymptomatic in more than $50 \%$ of the cases ${ }^{1-2}$ and is usually discovered incidentally during chest $X$-ray examination. Additionally, it usually derives from the visceral pleura $(60-80 \%)$ and accounts for $5 \%$ of pleural tumors. Its symptoms include cough, chest pain, and dyspnea ${ }^{3}$. Peak incidence occurs in the sixth and seventh decades of life, with both sexes equally affected $^{2}$. Radiographic features include a solitary round or oval opacification often with continuity with the chest wall or located in the interlobar fissure ${ }^{1}$. "The incomplete border sign" of extrapleural lesions is useful to differentiate SFTPs from lung masses. Because extrapleural lesions may exhibit tapered borders, posteroanterior radiography results in an ill-defined margin ${ }^{4}$. Pleural effusion is reported in
$6-17 \%$ of patients. Tumor size above $10 \mathrm{~cm}$, pleural effusion, and marked continuity with parietal pleura suggest malignant nature ${ }^{1-3}$.

CT typically shows homogeneous, well-defined, non-invasive, lobular, soft-tissue masses ${ }^{1}$. The tumor usually forms acute angles against adjacent pleural surfaces. A smoothly tapering margin adjacent to the tumor is the most characteristic finding that establishes the pleural location of these tumors. Mass effect on the adjacent lung and mediastinum is also a typical finding ${ }^{3}$.

Preoperative differential diagnosis includes lung carcinoma and intrapleural sarcomas. Posterior intrathoracic location suggests neurogenic tumor or round atelectasis. Anterior and medial locations raise the possibility of a thymic neoplasm, germ cell tumors, or teratoma ${ }^{3}$.

The treatment consists of complete surgical excision. The type of surgical resection differs according to the size, location and extent of invasion of the tumor. Prognosis is generally favorable. Recurrence may occur up to 17 years after resection, usually in the same hemithorax. The most important outcome predictors are morphological and histological indicators ${ }^{3}$.

This study reported a rare case of mesenchymal neoplasm of fibroblastic origin presented in a giant form. The literature on the subject is based mainly on reports and case series, therefore data on the presentation and management of this type of tumor can contribute to its diagnosis.

\section{Conflict of interests}

The authors declare that there is no conflict of interests regarding the publication of this paper.

Institution where the study was performed: Universidade Federal de Ciências da Saúde de Porto Alegre.

\section{REFERENCES}

1. Jadczak P, Guz W, Kaznowska E, Ramotowski R, Szalacha-Tarała E, Górecki A, et al. Solitary fibrous tumour of the pleura - cases analysis. Pol J Radiol. 2014;79:368-73. http:// dx.doi.org/10.12659/PJR.890525. PMid:25352940.
2. Rakovich G, Laflamme M, Ouellette $D$, Beauchamp G. Solitary fibrous tumour of the pleura: A case report. Can Respir J. 2010;17(3):113-4. PMid:20617210.

3. Abu Arab W. Solitary fibrous tumours of the pleura. Eur J Cardiothorac Surg. 2012;41(3):587-97. http://dx.doi.org/10.1093/ejcts/ezr009. PMid:22345180.

4. Cardinale L, Ardissone F, Garetto I, Marci V, Volpicelli G, Solitro F, et al. Imaging of benign solitary fibrous tumor of the pleura: a pictorial essay. Rare Tumors. 2010;2(1):e1. http:// dx.doi.org/10.4081/rt.2010.e1. PMid:21139938. 